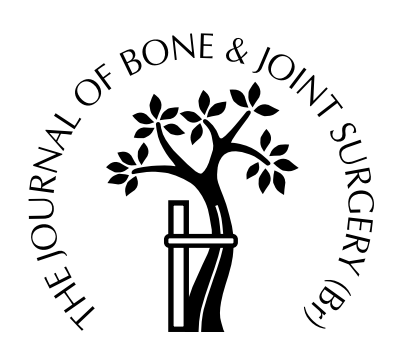

\title{
Sensory nerve fibres from lumbar intervertebral discs pass through rami communicantes
}

\author{
A POSSIBLE PATHWAY FOR DISCOGENIC LOW BACK PAIN \\ Kaoru Suseki, Yuzuru Takahashi, Kazuhisa Takahashi, \\ Tanemichi Chiba, Masatsune Yamagata, Hideshige Moriya \\ From Chiba University, Chiba, Japan
}

$\mathbf{I}^{\mathrm{t}}$ has been thought that lumbar intervertebral discs were innervated segmentally. We have previously shown that the L5-L6 intervertebral disc in the rat is innervated bilaterally from the $L 1$ and $L 2$ dorsal root ganglia through the paravertebral sympathetic trunks, but the pathways between the disc and the paravertebral sympathetic trunks were unknown.

We have now studied the spines of 17 rats to elucidate the exact pathways. We examined serial sections of the lumbar spine using immunohistochemistry for calcitonin gene-related peptide, a sensory nerve marker. We showed that these nerve fibres from the intervertebral disc ran through the sinuvertebral nerve into the rami communicantes, not into the corresponding segmental spinal nerve.

In the rat, sensory information from the lumbar intervertebral discs is conducted through rami communicantes. If this innervation pattern applies to man, simple decompression of the corresponding nerve root will not relieve discogenic pain. Anterior interbody fusion, with the denervation of rami communicantes, may be effective for such low back pain.

J Bone Joint Surg [Br] 1998;80-B:737-42.

Received 4 August 1997; Accepted after revision 8 January 1998

Lumbar intervertebral discs and facet joints are possible sources of low back pain, ${ }^{1-3}$ but they have been considered to have a segmental sensory innervation. Recent studies in

K. Suseki, MD, PhD

Y. Takahashi, MD, PhD

K. Takahashi, MD, PhD

M. Yamagata, MD, PhD

H. Moriya, $\mathrm{MD}, \mathrm{PhD}$

Department of Orthopaedic Surgery

T. Chiba, MD, PhD

Department of Anatomy

School of Medicine, Chiba University, 1-8-1, Inohana, Chuo-ku, Chiba City, Chiba 260, Japan.

Correspondence should be sent to Dr K. Suseki at the Department of Neurology and Biomedical Engineering, School of Medicine, The Johns Hopkins University, 605 Traylor Building, 720 Rutland Avenue, Baltimore, Maryland 21205, USA.

(C) 1998 British Editorial Society of Bone and Joint Surgery 0301-620X/98/48239\$2.00

VOL. 80-B, No. 4, JULY 1998 rats, however, have shown that the L5-L6 disc and part of the L5-L6 joint capsules are innervated by sensory neurones of the L1 and L2 dorsal root ganglia through the paravertebral sympathetic trunk, ${ }^{4-10}$ although the fibre pathways between the disc and the sympathetic trunk are not known. Many reports have described fibres connecting the sinuvertebral nerve from the disc to rami communicantes tethered to the paravertebral sympathetic trunk, but they were thought to be sympathetic postganglionic nerve fibres. ${ }^{11-15}$ Connections through the sinuvertebral nerve between the intervertebral disc and the rami communicantes have not yet been identified.

We have investigated the distribution and course of both sensory and sympathetic postganglionic nerve fibres to the lumbar intervertebral disc in rats, using immunohistochemical methods. We paid special attention to the connections with rami communicantes and the segmentally corresponding spinal nerve.

\section{Materials and Methods}

We anaesthetised 17 Sprague-Dawley rats at 0 to 7 days after birth by cooling to $4^{\circ} \mathrm{C}$. They were then transcardially perfused with $0.9 \%$ saline, followed by $100 \mathrm{ml}$ of $4 \%$ paraformaldehyde in $0.1 \mathrm{M}$ phosphate buffer $(\mathrm{pH}$ 7.4). The spinal column with its muscles from $\mathrm{T} 13$ to $\mathrm{S} 1$ was removed, immersed in the same fixative overnight at $4^{\circ} \mathrm{C}$, and then decalcified for four days in $10 \%$ ethylenediaminetetra-acetic acid (Wako Chemical, Tokyo, Japan). After storage in $0.01 \mathrm{M}$ phosphate-buffered saline (PBS) containing $20 \%$ sucrose for 24 hours at $4^{\circ} \mathrm{C}$, the samples were serially sectioned at $40 \mu \mathrm{m}$ in a sagittal plane on a cryostat, and the sections placed on slide glasses.

Endogenous tissue peroxidase activity was blocked by soaking the sections for 30 minutes in $0.3 \% \mathrm{H}_{2} \mathrm{O}_{2}$ solution in $0.01 \mathrm{M}$ PBS. The sections were immersed for 90 minutes in a blocking solution, $0.01 \mathrm{M}$ PBS containing $0.3 \%$ Triton $\mathrm{X}-100$ and $1 \%$ skim milk, and incubated overnight at $4^{\circ} \mathrm{C}$ with antisera (1:1000) to calcitonin gene-related peptide (CGRP; Cambridge Research Biochemicals, Cheshire, UK), dopamine $\beta$-hydroxylase (DBH; Eugene Tech International, Redgefield Park, New Jersey) or vasoactive intestinal polypeptide (VIP; Incstar Corporation, Stillwater, Minnesota). 


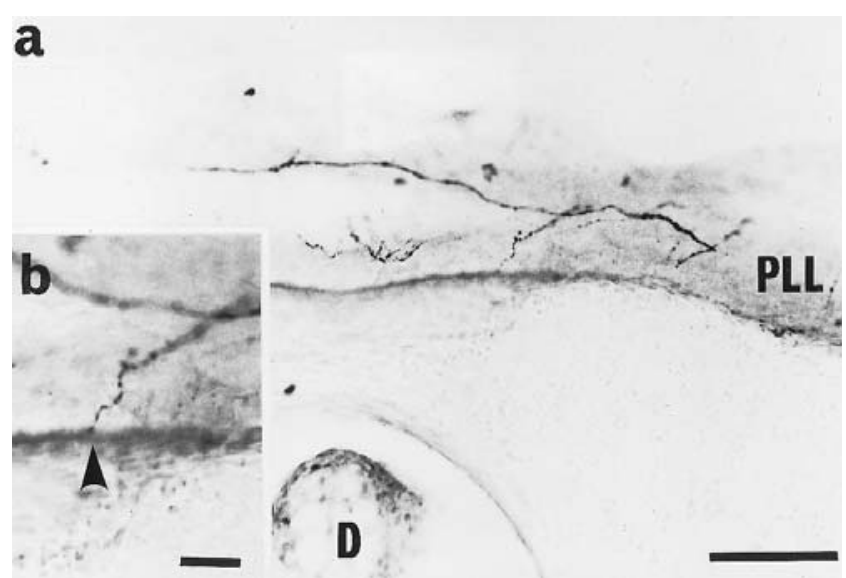

Fig. 1

Figure 1a-CGRP-immunoreactive nerve fibres in the posterior longitudinal ligament (PLL) and the superficial laminae of the annulus fibrosus of the L5-L6 disc in the sagittal plane. Dorsal is above, and cranial to the right in all sections. Most nerve fibres run rostrocaudally in the superficial plexus, and transversely or ventrodorsally in the deeper plexus, but some run from the superficial into the deeper plexus. Figure 1b (inset) is an enlarged view of part of the deeper plexus in Figure 1a (D, nucleus pulposus; arrowhead, CGRP-immunoreactive free nerve ending; bar $=100 \mu \mathrm{m}$ in Figure 1a and $25 \mu \mathrm{m}$ in Figure 1b)

Eleven specimens were processed with CGRP antisera, three with DBH antisera, and three with VIP antisera. They were processed by the indirect avidin-biotin complex technique using biotinylated goat anti-rabbit IgG (Vector Laboratories, Burlingame, California), avidin biotin reagent (Vector Laboratories) and diaminobenzidine with ammonium nickel sulphate. ${ }^{16}$ After each step, the slides were washed twice in $0.01 \mathrm{M}$ PBS.

Immunoreactive nerve fibres in the serial sections of segments T13 to L6 were observed by light stereomicroscopy, and sketched on sheets of paper using a drawing tube attached to the stereomicroscope (Nikon, Tokyo, Japan). The immunoreactive nerve fibres entering the intervertebral disc and its surrounding tissues were then reconstructed three-dimensionally by superimposition of the sketches.

For each immunostain, control sections were prepared by incubating sections in a blocking solution without the primary antibody.

\section{Results}

Calcitonin gene-related peptide (CGRP). Many CGRPimmunoreactive nerve fibres were seen in the posterior longitudinal ligament and the superficial laminae of the annulus fibrosus. They were both thin and thick and were located in two main plexuses. One was superficial, in the dorsal part of the posterior longitudinal ligament, and the other was deeper in the ventral part of the posterior longitudinal ligament and the superficial laminae of the annulus fibrosus. The two plexuses were connected by several fibres. In the superficial plexus, CGRP-immuno- reactive fibres were not confined only to the intervertebral regions. In the deeper plexus the CGRP-immunoreactive nerve fibres were more dense and were present only in the intervertebral regions near the annulus fibrosus (Fig. 1a), extending to immunoreactive free nerve endings in the superficial laminae of both ventral and dorsal parts of the annulus fibrosus (Fig. 1b). There were no CGRP-immunoreactive nerve fibres in the nucleus pulposus.

Most CGRP-immunoreactive nerve fibres in the posterior longitudinal ligament and the annulus fibrosus came from the sinuvertebral nerve proceeding into the nerve bundles in rami communicantes (Fig. 2). The latter were separated into two or more bundles, but could not be recognised as white or gray rami. Some CGRP-immunoreactive nerve fibres were traced from the annulus fibrosus to the rami communicantes completely (Fig. 3). Figure 4 shows a CGRPimmunoreactive nerve fibre connecting the sinuvertebral nerve with the rami communicantes. These connecting fibres were found in all segments from T13 to L6. No CGRP-immunoreactive nerve fibres were found to connect the sinuvertebral nerve with the corresponding segmental spinal nerve.

No CGRP-immunoreactive neurones were seen in the paravertebral sympathetic ganglion. Most of the CGRPimmunoreactive nerve fibres in the rami communicantes travelled cranially into the paravertebral sympathetic trunk (Fig. 5), although in L1 and L2 segments, they travelled only caudally. The courses of these nerve-fibre bundles around L4-L5 and L5-L6 intervertebral discs are shown schematically in Figure 6.

Dopamine $\beta$-hydroxylase (DBH). Many DBH-immunoreactive nerve fibres and some reactive nerve endings were seen in the posterior longitudinal ligament and the superficial laminae of the annulus fibrosus (Fig. 7). There were no DBH-immunoreactive nerve fibres in the nucleus pulposus. In both the ligament and the disc, the distribution of DBH-immunoreactive nerve fibres was similar to that of CGRP-immunoreactive fibres, but only thin DBH-immunoreactive fibres were present, most of them distant from blood vessels.

Most DBH-immunoreactive nerve fibres in the annulus fibrosus from L1 to L6 were followed into the sinuvertebral nerve, and on into the nerve bundles of rami communicantes (Fig. 8). Many DBH-immmunoreactive nerve fibres in the rami communicantes were connected to those in the paravertebral sympathetic trunk.

Vasoactive intestinal polypeptide (VIP). The distribution pattern of VIP-immunoreactive nerve fibres was very similar to that of the DBH-immunoreactive fibres, but there were more in the annulus fibrosus (Fig. 9). Most VIPimmunoreactive nerve fibres were thin and distant from blood vessels, and many travelled from the sinuvertebral nerve into rami communicantes in all segments from L1 to L6 (Fig. 10).

Control. None of the control sections without a primary antibody showed any immunostaining. 

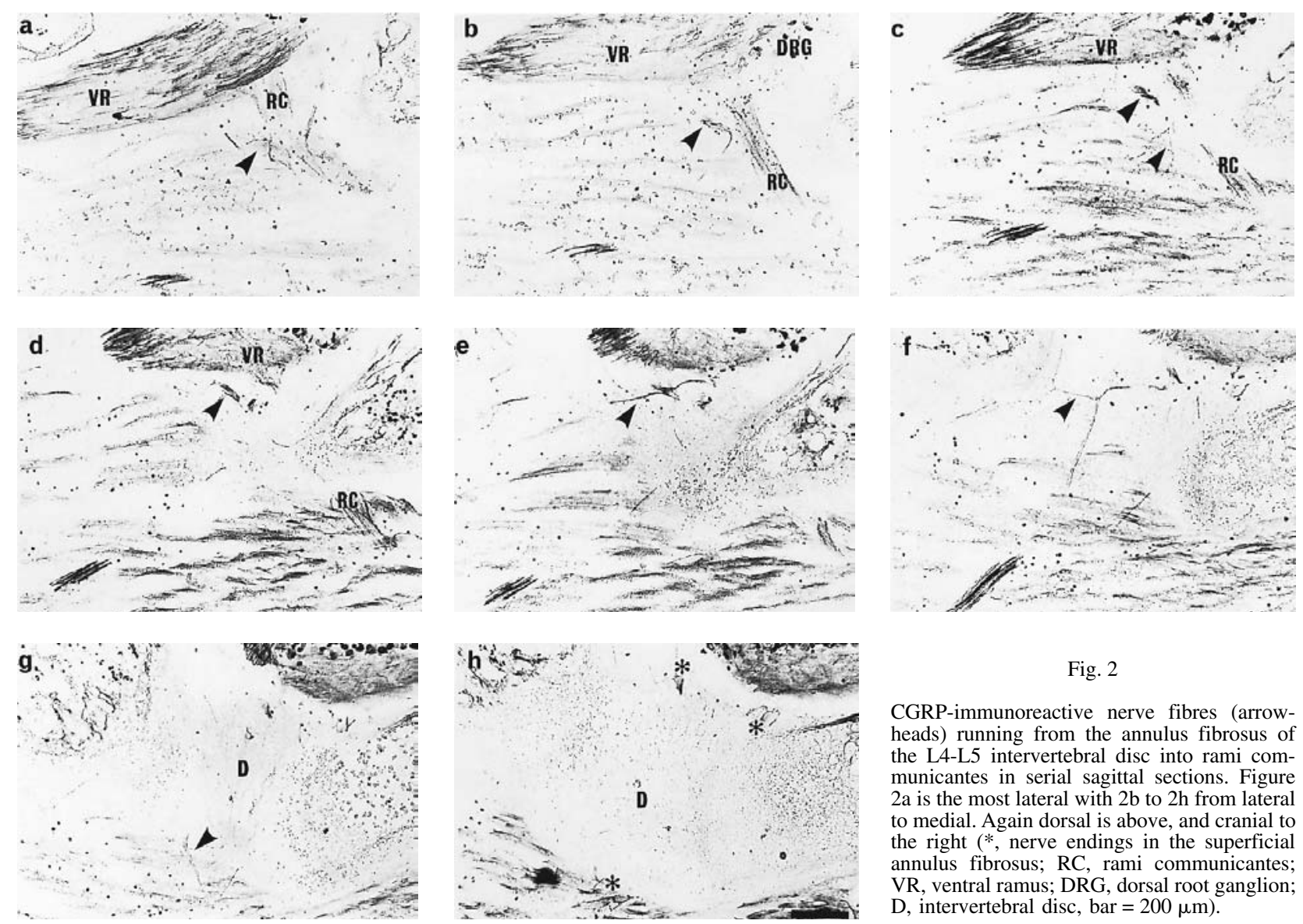

Fig. 2

CGRP-immunoreactive nerve fibres (arrowheads) running from the annulus fibrosus of the L4-L5 intervertebral disc into rami communicantes in serial sagittal sections. Figure $2 \mathrm{a}$ is the most lateral with $2 \mathrm{~b}$ to $2 \mathrm{~h}$ from lateral to medial. Again dorsal is above, and cranial to the right $(*$, nerve endings in the superficial annulus fibrosus; RC, rami communicantes; VR, ventral ramus; DRG, dorsal root ganglion; $\mathrm{D}$, intervertebral disc, bar $=200 \mu \mathrm{m}$ ).

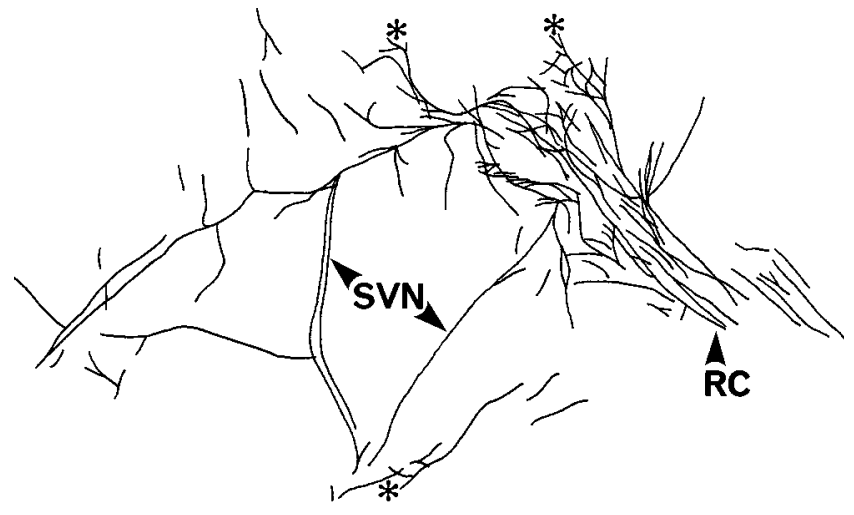

Fig. 3

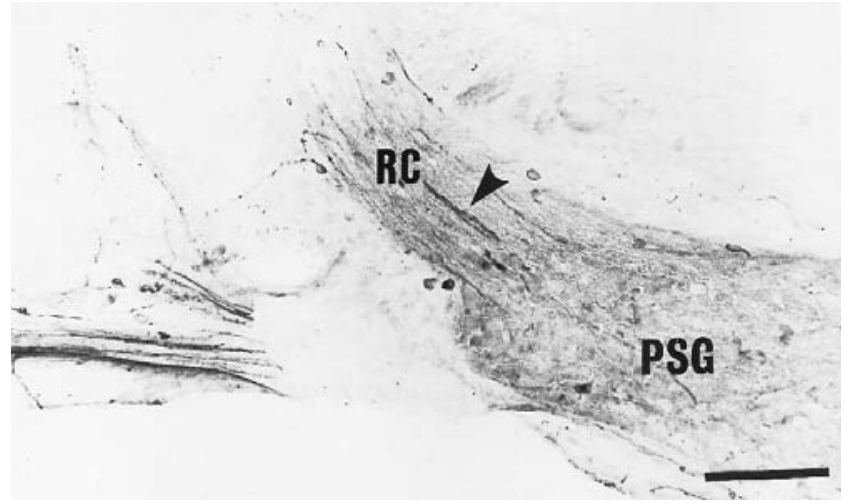

Fig. 5

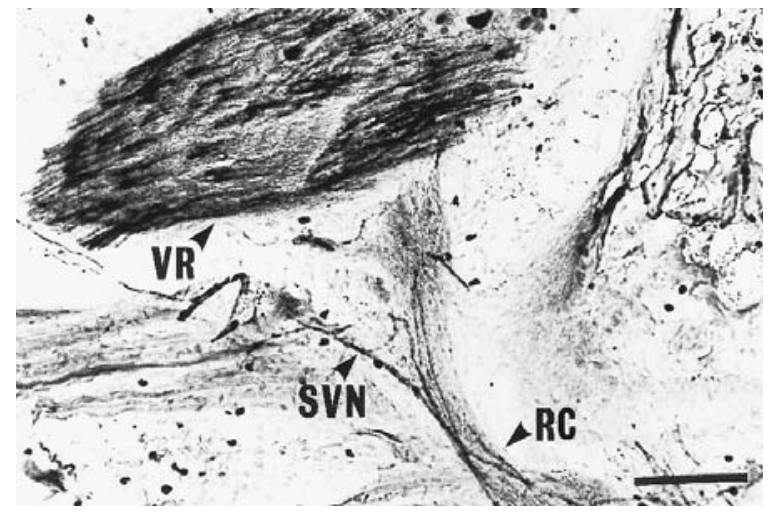

Fig. 4

Figure 3 - Diagram of the eight photographs in Figure 2, superimposed. Some CGRP-immunoreactive nerve fibres can be traced from the annulus (asterisks) into the rami communicantes (RC). Some from the ventral annulus run into the RC through the sinuvertebral nerves (SVN). Figure 4 - A CGRP-immunoreactive nerve fibre connects the sinuvertebral nerve (SVN) with the ramus communicans (RC) in a sagittal plane section of the right L5-L6 intervertebral foramen (VR, ventral ramus of the spinal nerve; bar $=200 \mu \mathrm{m}$ ). Figure 5 - CGRP-immunoreactive fibres connect the ramus communicans (RC) with the right paravertebral sympathetic trunk (arrowhead) in a sagittal plane section of the L3-L4 segment. No CGRP-immunoreactive neurones were found in the paravertebral sympathetic ganglion $(\mathrm{PSG})(\mathrm{bar}=200 \mu \mathrm{m})$. 


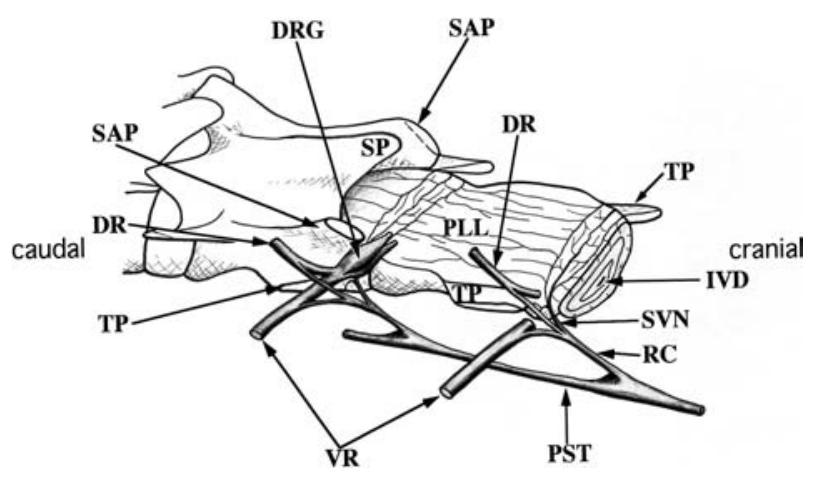

Fig. 6

Diagram of CGRP-immunoreactive fibre bundles around the L4-L5 and L5L6 intervertebral discs in rats (IVD, intervertebral disc; VR, ventral ramus of the spinal nerve; DR, dorsal ramus of the spinal nerve; DRG, dorsal root ganglion; PST, paravertebral sympathetic trunk; RC, ramus communicans; SVN, sinuvertebral nerve; PLL, posterior longitudinal ligament; SAP, superior articular process; SP, spinous process; TP, transverse process).

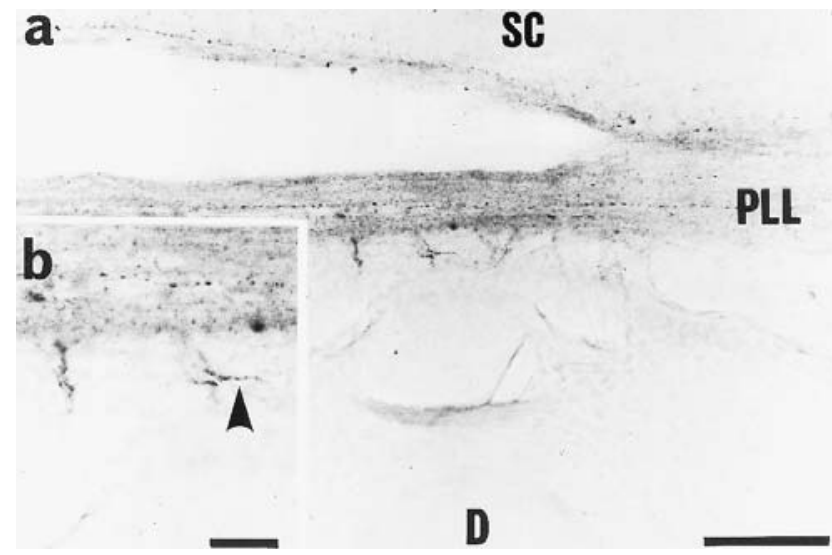

Fig. 7

\section{Discussion}

CGRP is reported to be a sensory nerve marker; ${ }^{17}$ we found no CGRP-immunoreactive neurones in paravertebral sympathetic ganglia. DBH and VIP are thought to be markers of sympathetic postganglionic nerves ${ }^{18,19}$ and VIP has been found in a few neurones in the dorsal root ganglion, but only in the thoracic and sacral areas. ${ }^{20}$ We therefore used VIP as a sympathetic postganglionic nerve marker in the lumbar spine.

It has been thought that the nerve fibres in the intervertebral disc derived bilaterally from the sinuvertebral nerves of the same and the adjacent segments, and that these were sensory nerve fibres originating from the corresponding spinal nerve and sympathetic postganglionic nerve fibres from the rami communicantes. ${ }^{2,11-14,21}$ Recent studies, however, have shown that in both the rat and man the

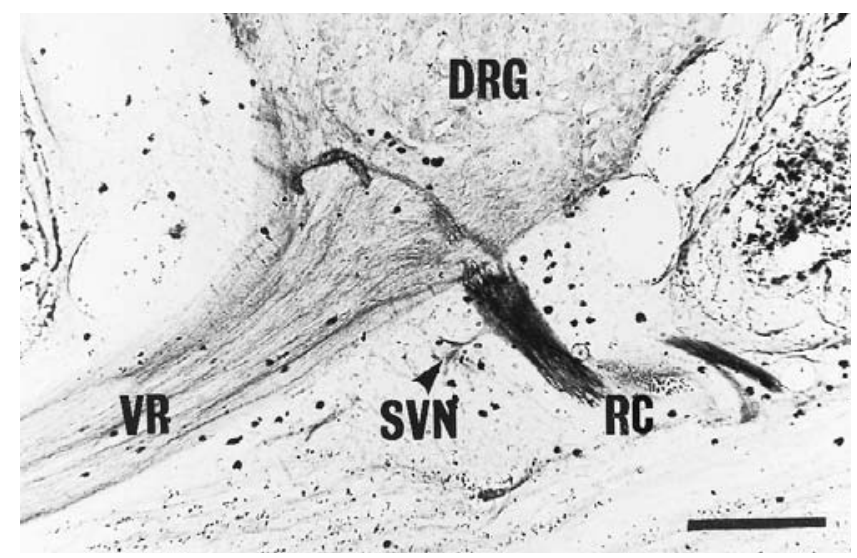

Fig. 8

Figure 7 - DHB-immunoreactive fibres in the posterior longitudinal ligament (PLL) and the superficial laminae of the annulus fibrosus of the L4-L5 intervertebral disc in a sagittal plane section. Most nerve fibres run rostrocaudally in the superficial plexus, and transversely or ventrodorsally in the deeper plexus, and some connect the two plexuses. Figure $7 \mathrm{~b}$ (inset) is an enlarged view of the deeper plexus (arrowhead, DBH-immunoreactive nerve ending; D, intervertebral disc; SC, spinal cord; bar $=100 \mu \mathrm{m}$ in Figure $7 \mathrm{a}$ and $25 \mu \mathrm{m}$ in Figure $7 \mathrm{~b}$ ). Figure $8-\mathrm{A}$ DBH-immunoreactive nerve fibre connecting the sinuvertebral nerve (SVN) with the RC in a sagittal plane section of the right L4-L5 intervertebral foramen. There were no DBH-positive neurones in the DRG (VR, ventral ramus; bar $=200 \mu \mathrm{m})$.

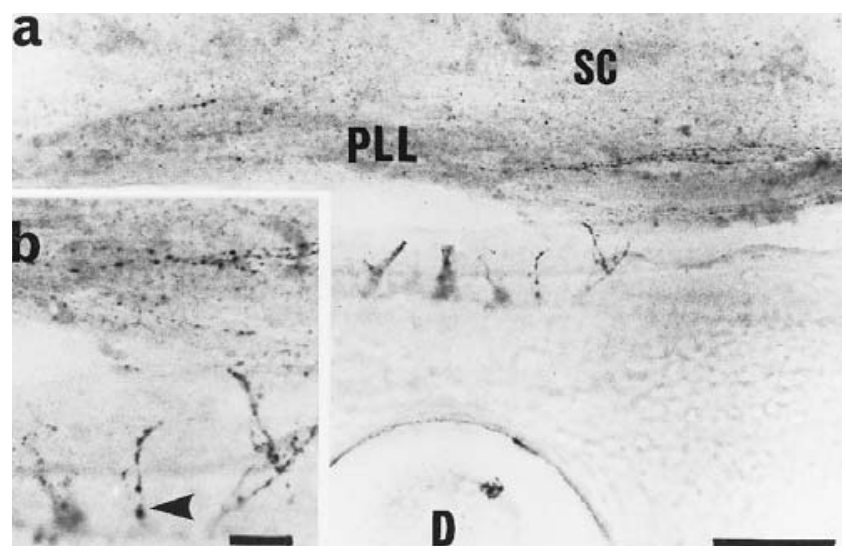

Fig. 9

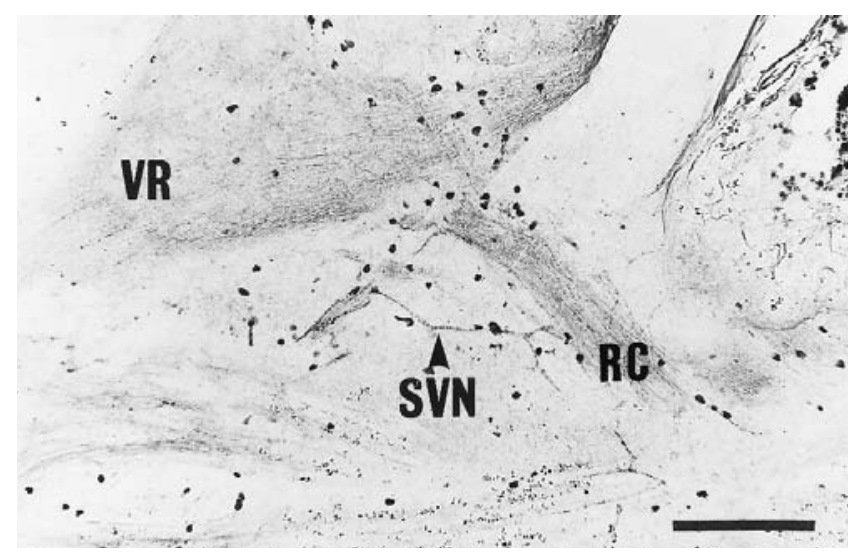

Fig. 10

Figure 9 - VIP-immunoreactive nerve fibres in the posterior longitudinal ligament (PLL) and the superficial annulus fibrosus at the L4-L5 intervertebral disc in a sagittal section. Most fibres run rostrocaudally in the superficial plexus, and transversely or ventrodorsally in the deeper plexus. Some fibres run from the superficial plexus into the deeper plexus. Figure 9b (inset) is an enlarged view of the deeper plexus (arrowhead, VIP-immunoreactive nerve ending; D, nucleus pulposus; SC, spinal cord; bar $=100 \mu \mathrm{m}$ in Figure $9 \mathrm{a}$ and $25 \mu \mathrm{m}$ in 9b). Figure $10-$ VIP-immunoreactive nerve fibres connecting the sinuvertebral nerve (SVN) with rami communicantes $(\mathrm{RC})$ in a sagittal section of the L3-L4 intervertebral foramen $($ bar $=200 \mu m)$. 
L5-L6 (L5-S1) intervertebral disc is innervated by sensory neurones in the L1 and L2 dorsal root ganglia, and not from the corresponding segmental levels. ${ }^{4-8}$ Using an acetylcholinesterase whole-mount method, Groen et $\mathrm{al}^{15}$ showed that the nerve fibres within the sinuvertebral nerve in man originated only from rami communicantes. It was not clear whether these connecting fibres were sensory, because both sensory and sympathetic postganglionic nerve fibres were stained by the acetylcholinesterase method. ${ }^{22}$ We have shown for the first time that CGRP-immunoreactive sensory nerve fibres connected the sinuvertebral nerve to the rami communicantes; we also found that no CGRP-immunoreactive sensory nerve fibres ran from the sinuvertebral nerve into the corresponding segmental spinal nerve. This suggests that all nerve fibres within the sinuvertebral nerve may connect only with the rami communicantes.

We also traced some CGRP-immunoreactive nerve fibres from the annulus fibrosus to the rami communicantes for the first time; this indicated that sensory information from lumbar intervertebral discs is conducted through the rami communicantes, and not through the corresponding segmental spinal nerve. We also found many CGRP-immunoreactive nerve fibres in rami communicantes connecting with the paravertebral sympathetic trunk, showing that the sensory pathways between the disc and the paravertebral sympathetic trunk are in the rami communicantes. These results lead us to believe that in the rat sensory nerve fibres from the L5-L6 disc pass bilaterally through the L4, L5 and L6 sinuvertebral nerves, to enter both paravertebral sympathetic trunks through L4, L5 and L6 rami communicantes, and finally reach the L1 and/or L2 dorsal root ganglia through L1 or L2 rami communicantes as reported previously (Fig. 11).

We found a total lack of all CGRP-, DBH-, and VIPimmunoreactive nerve fibres in the deeper parts of the intervertebral disc, as previously reported for both $\operatorname{man}^{23}$ and the rat. ${ }^{24-26}$ There have been reports, however, of sensory nerve fibres in the deeper parts of diseased discs in $\operatorname{man}^{27,28}$ and also in the healing area of the medial collateral ligament of the rabbit knee. ${ }^{29}$ In a degenerative intervertebral disc, these fibres may grow into deeper parts and play a role in discogenic low back pain and in the repair process.

We found many DBH and VIP-immunoreactive sympathetic postganglionic nerve endings in the posterior longitudinal ligament and the superficial laminae of the annulus. The main function of these sympathetic postganglionic nerve fibres seems to be vasomotor regulation, but some were distant from blood vessels suggesting that they have other functions. Gillette, Kramis and Roberts, ${ }^{30}$ working on cats, considered that sympathetic postganglionic nerve fibres in the paravertebral sympathetic trunk regulate sensory neurones of the spinal dorsal horn which project to lumbar paravertebral tissues. In addition, in the rat, VIP-immunoreactive sympathetic postganglionic nerve fibres have been reported to regulate the metabolism of bone

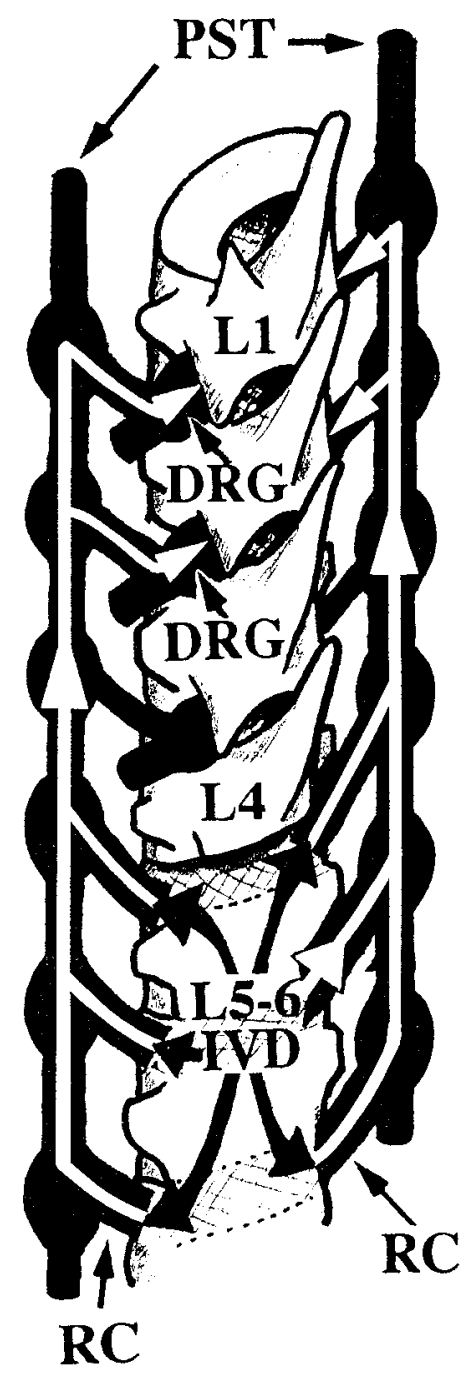

Fig. 11

Diagram of postulated sensory pathways from the L5-L6 intervertebral disc bilaterally to the L1 and/or L2 DRG, shown as long black and white arrows (IVD, intervertebral disc; RC, ramus communicans; PST, paravertebral sympathetic trunk).

and ligament tissues, ${ }^{24,31}$ and Imai et $\mathrm{al}^{26}$ reported that sympathetic postganglionic nerve fibres alter the properties of the sensory axons of the posterior longitudinal ligament in the rat. Some of the sympathetic postganglionic nerve endings in the posterior longitudinal ligament and the disc may therefore have some sensory and metabolic roles.

The nervous system of the rat is very similar to that of man. In both, the L5-L6 (L5-S1) disc is innervated nonsegmentally and bilaterally from the L1 and L2 dorsal root ganglia, ${ }^{4-7}$ and sympathetic nerve fibres originate from the T1 to L2 myelomeres. ${ }^{22,32-35}$ Hence, there is a strong possibility that the sensory innervation pattern which we found in the rat is present in man and therefore this explains the report of El Mahdi, Abdel-Latif and Janko ${ }^{36}$ that lumbar sympathetic block is an effective treatment for discogenic pain. It also implies that decompression of a 
spinal nerve may not relieve disc pain from the same segment, because the sensory nerve fibres are not in the corresponding segmental spinal nerve. To cure discogenic pain, it may be necessary to remove the intervertebral disc and to denervate the corresponding rami communicantes from which the intervertebral area may be reinnervated. Miyamoto $^{37}$ reported that anterior discectomy and interbody fusion completely relieved discogenic pain for long periods, but it seems possible that the anterior discectomy and interbody fusion also denervated the rami communicantes, which would account for the success of the procedure.

No benefits in any form have been received or will be received from a commercial party related directly or indirectly to the subject of this article.

\section{References}

1. Mooney V, Robertson J. The facet syndrome. Clin Orthop 1976;115: 149-56.

2. Wiberg G. Back pain in relation to the nerve supply of the intervertebral disc. Acta Orthop Scand 1949;19:211-21.

3. Weinstein J, Claverie W, Gibson S. The pain of discography. Spine 1988;13:1344-8.

4. Takahashi Y, Nakajima Y, Sakamoto T, Moriya H, Takahashi K. Capsaicin applied to rat lumbar intervertebral disc causes extravasation in the groin skin: a possible mechanism of referred pain of the intervertebral disc. Neurosci Lett 1993;161:1-3.

5. Morinaga T, Takahashi K, Yamagata M, et al. Sensory innervation to the anterior portion of lumbar intervertebral disc. Spine 1996;21: 1848-51.

6. Nakamura S, Takahashi K, Takahashi Y, Yamagata M, Monija H. The afferent pathways of discogenic low-back pain: evaluation of L2 spinal nerve infiltration. J Bone Joint Surg [Br] 1996;78-B: 606-12.

7. Takahashi Y, Morinaga T, Nakamura $S$, et al. Neural connection between the ventral portion of the lumbar intervertebral disc and the groin skin. J Neurosurg 1996;85:323-8.

8. Nakamura S, Takahashi K, Takahashi Y, et al. Origin of nerves supplying the posterior portion of lumbar intervertebral discs in rats. Spine 1996;21:917-24.

9. Suseki K, Takahasi Y, Takahashi K, et al. CGRP-immunoreactive nerve fibers projecting to lumbar facet joints through the paravertebral sympathetic trunk in rats. Neurosci Lett 1996;221:41-4.

10. Suseki K, Takahashi Y, Takahashi K, et al. Innervation of the lumbar facet joints: origins and functions. Spine 1997;22:477-85.

11. Pedersen HE, Blunck CF, Gardner E. The anatomy of lumbosacral posterior rami and meningeal branches of spinal nerves (sinu-vertebral nerves). J Bone Joint Surg [Am] 1956;38-A:377-91.

12. Kimmel DL. Innervation of spinal dura mater and dura mater of the posterior cranial fossa. Neurology 1961;11:800-9.

13. Edgar MA, Ghadially JA. Innervation of the lumbar spine. Clin Orthop 1976;115:35-41.

14. Bogduk N, Tynan W, Wilson AS. The nerve supply to the human lumbar intervertebral discs. J Anat 1981;132:39-56.

15. Groen GJ, Baljet B, Drukker J. Nerves and nerve plexuses of the human vertebral column. Am J Anat 1990;188:282-96.

16. Ashton IK, Ashton BA, Gibson SJ, et al. Morphological basis for back pain: the demonstration of nerve fibers and neuropeptides in the lumbar facet joint capsule but not in ligamentum flavum. J Orthop Res 1992;10:72-8
17. Lee Y, Takami K, Kawai Y, et al. Distribution of calcitonin generelated peptide in the rat peripheral nervous system with reference to its coexistence with substance P. Neuroscience 1985;15:1227-37.

18. Hartman BK, Zide D, Udenfriend $\mathbf{S}$. The use of dopamine $\beta$-hydroxylase as a marker for the central noradrenergic nervous system in rat brain. Proc Natl Acad Sci USA 1972;69:2722-6.

19. Lundberg JM, Hökfelt T, Schultzberg M, et al. Occurrence of vasoactive intestinal polypeptide (VIP)-like immunoreactivity in certain cholinergic neurons of the cat: evidence from combined immunohistochemistry and acetylcholinesterase staining. Neuroscience 1979; 4:1539-59.

20. Honda CN, Rethelyi M, Petrusz P. Preferential immunohistochemical localization of vasoactive intestinal polypeptide (VIP) in the sacral spinal cord of the cat: light and electron microscopic observations. J Neurosci 1983;3:2183-96.

21. Luschka Hv. Die Nerven des menschlichen Wirbelkanales. Tübingen: H Laupp, 1850.

22. Coggeshall RE, Emery DG, Ito H, Maynard CW. Unmyelinated and small myelinated axons in rat ventral roots. J Comp Neurol 1977; 173:175-84.

23. Ashton IK, Roberts S, Jaffray DC, Polak JM, Eisenstein SM. Neuropeptides in the human intervertebral disc. J Orthop Res 1994; 12:186-92.

24. Von During M, Fricke B, Dahlmann A. Topography and distribution of nerve fibers in the posterior longitudinal ligament of the rat: an immunocytochemical and electron-microscopical study. Cell Tissue Res 1995;281:325-38.

25. Imai S, Hukuda S, Maeda T. Dually innervating nociceptive networks in the rat lumbar posterior longitudinal ligaments. Spine 1995; 20:2086-92

26. Imai S, Konttinen YT, Tokunaga Y, et al. Tyrosine hydroxylaseimmunoreactive nerve fibers in rat posterior longitudinal ligament. J Auton Nerv Syst 1997;63:51-60.

27. Grönblad M, Weinstein JN, Santavirta S. Immunohistochemical observations on spinal tissue innervation: a review of hypothetical mechanisms of back pain. Acta Orthop Scand 1991;62:614-22.

28. Freemont AJ, Peacock TE, Goupille P, et al. Nerve ingrowth into diseased intervertebral disc in chronic back pain. Lancet 1997;350: 178-81.

29. Grönblad M, Korkala O, Konttinen YT, Kuokkanen H, Liesi P. Immunoreactive neuropeptides in nerves in ligamentous tissue: an experimental neuroimmunohistochemical study. Clin Orthop 1991; 265:291-6.

30. Gillette RG, Kramis RC, Roberts WJ. Sympathetic activation of cat spinal neurons responsive to noxious stimulation of deep tissues in the low back. Pain 1994;56:31-42.

31. Hohmann EL, Elde RP, Rysavy JA, Einzig S, Gebhard RL. Innervation of periosteum and bone by sympathetic vasoactive intestinal peptide-containing nerve fibers. Science 1986;232:868-71.

32. Mitchell GAG. Anatomy of the autonomic nervous system. Edinburgh: E \& S Livingstone, 1953:201-12,257-9.

33. Johnson RH, Spalding JMK. Disorders of the autonomic nervous system. Oxford: Blackwell Scientific Publications, 1974:1-22.

34. Williams PL, Warwick R, Dyson M, Bannister LH. Gray's anatomy 37th ed. New York: Churchill Livingstone, 1989b:1123-53.

35. Gabella G. Autonomic nervous system. In: Paxinos G, ed. The rat nervous system. 2nd ed. San Diego: Academic Press, 1995:81-103.

36. El-Mahdi MA, Abdel-Latif FY, Janko M. The spinal nerve root 'innervation' and a new concept of the clinicopathological interrelations in back pain and sciatica. Neurochirurgia Stuttg 1981;24: $137-41$.

37. Miyamoto K. Long-term follow-up results of anterior discectomy and interbody fusion for lumbar disc herniation. Nippon Seikeigeka Gakkai Zasshi 1991;65:1179-90. 